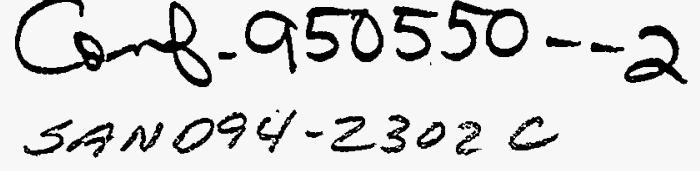

\title{
HIGH STRAIN-RATE TESTING OF PARACHUTE MATERIALS*
}

\author{
Kenneth W. Gwinn \\ John J. Totten \\ Donald E. Waye \\ Material and Structural Mechanics Experimental Mechanics Fluid/Structure Interactions \\ Sandia National Laboratories \\ Albuquerque, NM 87185
}

\begin{abstract}
Research at Sandia National Laboratories has shown a strain rate dependence of many materials used in the production of parachutes. Differences in strength of $30 \%$ have been found between strain rates of $12 \mathrm{sec}^{-1}$ and slow rates normally used to define material properties for lightweight nylon cloth. These structures are sometimes deployed in a rapid fashion and the loading is experienced in milliseconds; the production of material data in the same loading regime is required for full understanding of material response. Also, material behavior suitable for structural analysis of these structures is required for successful analysis. This is especially important when different materials are used in the same fabric structure. Determining the distribution of load to various portions of a nylon and Kevlar parachute requires the correct moduli and material behavior in the analytical model.
\end{abstract}

The effect of strain rate on the material properties of nylon and Kevlar components commonly used in parachute construction are reported in this paper. These properties are suitable for use in analytical models of these fabric structures.

\section{Introduction}

Using analysis tools of structural mechanics on high performance fabric structures is a new area of research at Sandia National Laboratories. Several successful examples have included studies of cross parachutes, analyses of the Jet Propulsion Laboratory Mars Pathfinder Airbag System, and, most recently, the design and analysis of a new generation automobile airbag $[1,2,3]$. Supplying the correct material behavior is of prime importance to the successful analysis and design of

*This work was performed at Sandia National Laboratories, Albuquerque, New Mexico, supported by the United States Department of Energy under Contract DE-AC04-94AL85000.

This paper is declared a work of the U.S. Government and is not subject to copyright protection in the United States. these structures. The behavior of the materials under representative rates of loading must also be provided because many of these structures are used in dynamic environments. The high strain-rate measurement of fabric behavior at cold, ambient, and high temperatures is even more challenging, but necessary, as differences of $30 \%$ are found for various environmental combinations.

The purpose of this paper is to provide the basis of high strain rate material properties for the engineering of parachute systems and other high performance fabric structures. A description of the test method is given along with results from representative materials. The difficulties of adapting equipment normally used to test metals for the testing of fabrics is also discussed. Additionally, high speed photography was necessary for the measurement of strain and strain rate of the fabric. All of these complicating factors are necessary for the measurement of fabric high strain rate material behavior.

\section{Test Method}

Data is required for representative material types used in parachute construction, at the environmental extremes of use. This includes the combination of temperature and strain rate. Samples were tested at 4 decades of strain rates for the temperatures of $-40^{\circ} \mathrm{F}$, ambient, and $160^{\circ} \mathrm{F}$.

The need for uniaxial properties of the various fabric or woven components precludes the use of 'grab' grips commonly used in fabric testing. Instead, cylindrical 'wrap' grips are used for all the testing reported here. These wrap grips produce an even state of strain across the full width of the material sample. Fabric slipping has been observed when grab grips were used, as well as constraint of the fabric edges, normal to the direction of 


\section{DISCLAIMER}

This report was prepared as an account of work sponsored by an agency of the United States Government. Neither the United States Government nor any agency thereof, nor any of their employees, makes any warranty, express or implied, or assumes any legal liability or responsibility for the accuracy, completeness, or usefulness of any information, apparatus, product, or process disclosed, or represents that its use would not infringe privately owned rights. Reference herein to any specific commercial product, process, or service by trade name, trademark, manufacturer, or otherwise does not necessarily constitute or imply its endorsement, recommendation, or favoring by the United States Government or any agency thereof. The views and opinions of authors expressed herein do not necessarily state or reflect those of the United States Government or any agency thereof. 


\section{DISCLAIMER}

Portions of this document may be illegible in electronic image products. Images are produced from the best available original document. 
load. Because uniaxial behavior is required to define the material properties for analytical behavior models, only cylindrical grips are used.

One complicating detail of using these wrap grips is that straining of the material occurs around some unknown portion of the grip. This means that the gage length, and therefore the strain, is not directly measurable from the crosshead of the test machine. Another method of measuring strain is therefore required, and the authors chose to use high speed photography to measure the strain in one sample of each type of material. The details of this measurement, the test technique and procedure follows.

\section{Test Equipment and Setup}

In the testing of the parachute materials by the Experimental Mechanics Department (Sandia National Laboratories, Livermore, $\mathrm{CA}$ ), the following equipment and conditions were used.

The testing was performed on a MTS model 312.12 50,000 load frame with a 20,000 hydraulic actuator. The actuator is equipped with both a 15 gallon/minute servo valve and a 200 gallon/minute poppit valve which allows control at standard testing rates as well as high rates up to approximately 200 inches per second (high rates run open loop). The control of the MTS load frame is accomplished using the MTS 458.20 Micro console which also indicates and furnishes a voltage output proportional to the stroke of the actuator. This test apparatus is shown in Figure 1.

For temperature conditioning, an Instron 3110 temperature chamber is installed in the test frame which allows both heating and cooling to the test temperatures (an internal thermocouple is used to control the chamber temperature). The temperature of the testing volume is also checked by placing an additional thermocouple in the chamber near the test area. The chamber is heated by resistively heating all surfaces of the chamber and kept at a constant temperature with a small fan which circulates the heated air within the chamber. Cooling is accomplished by the introduction of liquid nitrogen through a temperature controlled valve. The temperature conditioning unit installed in the test machine frame is shown in Figure 1 (door of conditioning unit open for photograph).
Because of the high loading rate, a standard strain gage load cell cannot be used. The load data is sensed using a Kistler 9061A quartz load washer conditioned with a Kistler 5026 dual mode charge amplifier which is calibrated against a standard load cell. The charge amplifier provides load output signals proportional to the applied load without filtering out the high rate data. The output is filtered at $350 \mathrm{KHz}$ which is the standard output filter for the 5026 charge amplifier.

Both the Load signal and the stroke signal are recorded on a Nicolet Digital Oscilloscope. Each data trace is recorded with 4000 data points on screen, which are then transferred to a $31 / 2$ floppy disk. This data is later converted to ASCII data which can be plotted using a standard spread sheet or plotting package. Samples were taken every $20 \mu \mathrm{sec}$ to gain accurate measure of the load/stroke time history of the test.

The fabric is held with a pair of standard fabric testing grips which allows the gripping of the nylon material in such a way that no sharp edges are encountered by the material. An appropriate gage length is selected, based on the amount of strain observed in the high speed photography.

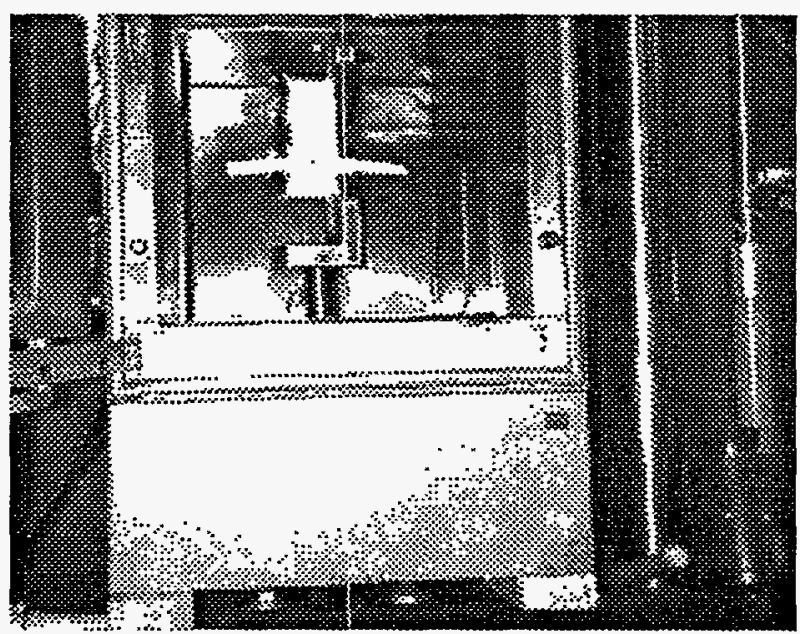

Figure 1. Test Machine with Temperature Conditioning Unit Installed.

\section{Strain Measurement}

A representative strain measurement was made for each material type, at each of the temperature conditions mentioned earlier. High speed photography recorded the extension of the gage marks made on the samples. The 
camera operated at 6,000 frames/sec with $16 \mathrm{~mm}$ film and included registered timing marks for film speed verification. From this data a measure of engineering strain is possible. Postprocessing of the individual film records was accomplished by simply measuring the relative stretching of the gage marks for the final frames using a data analyzing projector.

Because a square grid was used for most of the samples, a measure of the Poisson's ratio for the material can also be made. This is especially useful for the analytical material behavior, as these fabrics exhibit orthotropic behavior. Direct measure of the fill/warp/bias properties must be made to accurately model these behavior.

\section{Test Procedure}

The testing was completed as follows:

- Samples were marked with a 1 inch square grid (small width samples marked in axis of pull only),

- Samples were then baked at $212^{\circ} \mathrm{F}$ for a minimum of 1 hour to remove any residual humidity effects,

- Samples were transferred to sealed plastic bags for storage prior to testing,

- Initial length between grips set to 3.5 in for sample installation (clamp installed to prevent lower jaw from slipping and damaging the grip or the test machine during stopping of the lower grip),

- Grips were moved together 1 in to allow machine to achieve speed before straining sample,

- Samples were tested; storing displacement, load, and time for each event,

- Peak breaking load noted from each sample using oscilloscope record,

- Data from salient tests removed from disk, filtered, and plotted over useful range of data,

- Peak sample strengths from at least 3 tests were averaged to produce the data presented here for each sample type,

- Engineering strains were measured from the high speed photographic coverage by measuring the grid one frame prior to break (Poisson's ratio was similarly obtained from the cross-axis measurement of the strain, and dividing by the axis of pull strain measure).

- For the hot tests, samples were pre-heated, then placed in the chamber for $\sim 15$ minutes before the test to equilibrate to test temperature. Temperature was measured in the air as well as on the wrap grips. A similar procedure was used for the cold samples.

\section{Test Results}

A sample test track for $1 / 2$ by 550 nylon webbing is shown in Figure 2 (load vs. time at $165^{\circ} \mathrm{F}$ ). This test result has not been smoothed and the dynamics of the high speed test are evident from the test track.

\section{$1 / 2 \times 550$ Nylon - Hot, Test Data}

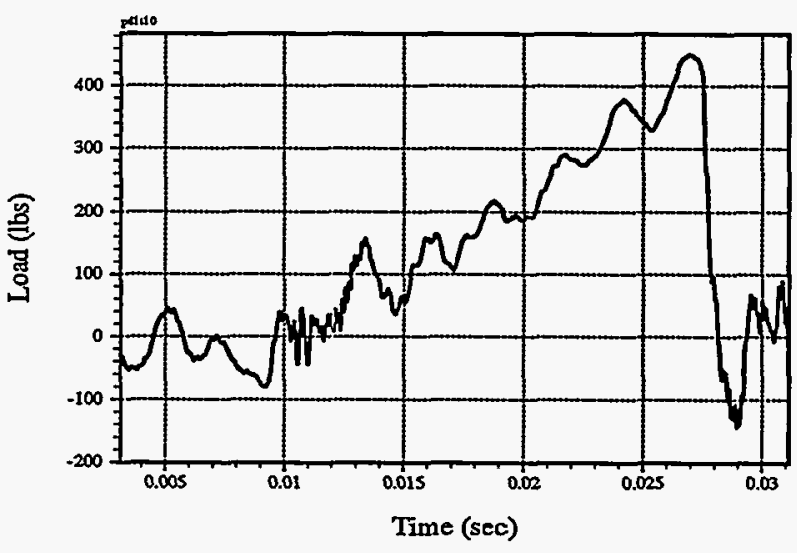

Figure 2. Nylon Web Example

The test results are arranged and discussed in several sections; temperature effects, strain rate effects, and strain-to-failure for both the kevlar and the nylon materials.

\section{Temperature Effects at High Strain-Rate}

The effects of temperature for the high strain-rate testing of nylon materials are summarized in Table 1; similar results are shown for Kevlar parachute materials in Table 2. Marked differences are found across the temperature range tested. A detailed discussion of these results follows.

The effects of strain-rate are presented for nylon parachute materials in Table 3, and similarly for the Kevlar material in Table 4. The nylon samples showed a marked dependence on strain-rate, but the Kevlar showed almost no dependence. It should be noted that the $0.012 \mathrm{sec}^{-1}$ strain rate is produced by the 'static' crosshead rate of $12 \mathrm{in} / \mathrm{min}$, which is commonly used. Also, the samples noted with an asterisk were obtained from wrap grips which had a 4 in diameter instead of the 2 in diameter grips used in the high strain-rate testing, 
Table 1. High Strain-Rate Temperature Effects for Nylon Parachute Materials

\begin{tabular}{|c|c|c|c|c|}
\hline $\begin{array}{l}\text { Temperature } \\
\text { Sample Type }\end{array}$ & \multicolumn{3}{|c|}{$\begin{array}{l}\text { Average Strength in Pounds at Temperature } \\
\text { (\% change from ambient strength) }\end{array}$} & $\begin{array}{l}\text { Total \% Change } \\
\text { Cold to Hot }\end{array}$ \\
\hline 2 x 550 Ribbon & $\begin{array}{c}580 \\
(19 \%)\end{array}$ & 486 & $\begin{array}{c}394 \\
(-19 \%)\end{array}$ & $(-32 \%)$ \\
\hline $1 / 2 \times 550$ Webbing & $\begin{array}{c}654 \\
(10 \%)\end{array}$ & 594 & $\begin{array}{c}512 \\
(-14 \%)\end{array}$ & $(-22 \%)$ \\
\hline $2 \times 1000$ Ribbon & $\begin{array}{l}1040 \\
(6 \%)\end{array}$ & 977 & $\begin{array}{c}828 \\
(-15 \%)\end{array}$ & $(-20 \%)$ \\
\hline $2 \times 2200$ Ribbon & $\begin{array}{c}2209 \\
(17 \%)\end{array}$ & 1886 & $\begin{array}{c}1677 \\
(-11 \%)\end{array}$ & $(-24 \%)$ \\
\hline $\begin{array}{l}1 \times 6000 \text { Webbing } \\
\text { MIL-W-27657 }\end{array}$ & $\begin{array}{c}5452 \\
(20 \%)\end{array}$ & 4528 & $\begin{array}{l}4273 \\
(-6 \%)\end{array}$ & $(-22 \%)$ \\
\hline $\begin{array}{l}1 \times 6000 \text { Webbing } \\
\text { MIL-W-4088 }\end{array}$ & $\begin{array}{c}5756 \\
(10 \%)\end{array}$ & 4528 & $\begin{array}{l}4273 \\
(-8 \%)\end{array}$ & $(-26 \%)$ \\
\hline
\end{tabular}

Table 2. High Strain-Rate Temperature Effects for Kevlar Parachute Materials

\begin{tabular}{|c|c|c|c|c|}
\hline $\begin{array}{l}\text { Temperature } \\
\text { Sample Type }\end{array}$ & \multicolumn{3}{|c|}{$\begin{array}{l}\text { Average Strength in Pounds at Temperature } \\
\text { (\% change from ambient strength) }\end{array}$} & $\begin{array}{l}\text { Total \% Change } \\
\text { Cold to Hot }\end{array}$ \\
\hline $1 \times 5000$ Webbing & $\begin{array}{l}4952 \\
(-3 \%)\end{array}$ & 5089 & $\begin{array}{l}4825 \\
(-5 \%)\end{array}$ & $(-3 \%)$ \\
\hline $1 \times 6000$ Webbing & $\begin{array}{l}6248 \\
(-1 \%)\end{array}$ & 6289 & $\begin{array}{l}6358 \\
(1 \%)\end{array}$ & $(2 \%)$ \\
\hline $1 / 2 \times 550$ Webbing & $\begin{array}{c}491 \\
(-10 \%)\end{array}$ & 543 & $\begin{array}{c}559 \\
(3 \%)\end{array}$ & $(14 \%)$ \\
\hline
\end{tabular}

and were generally slightly higher than those observed on the high strain-rate machine.

Strain-to-failure measures from the high strain-rate tests showed mixed results (all strains reported here are engineering strains). The lighter weight nylon materials (550 $\mathrm{lb}$ designators) showed strain to failure in the $13-18 \%$ range. The $1000 \mathrm{lb}$ nylon samples were found to strain $20-23 \%$, while the $6000 \mathrm{lb}$ nylon samples strained in the 16 - $18 \%$ range (the $1 \times 6000$ webbing MIL-W-4088 showed strain of $21 \%$ for the cold test, the only data available for this webbing). These strain measures were independent from temperature effects.The Kevlar samples all strained $5-7 \%$ at failure, regardless of temperature. Both the nylon and Kevlar exhibited linear strainto-failure, as illustrated in Figure 2.

Nylon cloth, 2.25 oz./yard, was also tested in the warp 
Table 3. Nylon Strain-Rate Dependent Strengths for Parachute Materials

\begin{tabular}{|c|c|c|c|c|c|}
\hline $\begin{array}{c}\text { Strain Rate (1/sec) } \\
\text { Sample Type }\end{array}$ & 0.012 & $\begin{array}{r}0.12 \\
\text { verage } S\end{array}$ & $\begin{array}{r}1.2 \\
\text { ength }\end{array}$ & 12 & $\begin{array}{l}\text { Percent } \\
\text { Change - } \\
\text { Slow to Fast }\end{array}$ \\
\hline $2 \times 550$ Ribbon & $746^{*}$ & & & 486 & $-35 \%$ \\
\hline $1 / 2 \times 550$ Webbing & $726^{*}$ & & & 594 & $-18 \%$ \\
\hline $2 \times 1000$ Ribbon & $1258 *$ & & & 977 & $-22 \%$ \\
\hline $2 \times 2200$ Ribbon & $2970^{*}$ & & & 1886 & $-37 \%$ \\
\hline $\begin{array}{l}1 \times 6000 \text { Webbing } \\
\text { Mil-W-27657 }\end{array}$ & $\begin{array}{c}6068 \\
7088^{*}\end{array}$ & 5321 & 5389 & 4528 & $-25 \%$ \\
\hline $\begin{array}{l}1 \times 6000 \text { Webbing } \\
\text { MIL-W-4088 }\end{array}$ & $7118^{*}$ & & & 5253 & $-26 \%$ \\
\hline
\end{tabular}

Note: Samples noted with * were from 4 in dia wrap grips, otherwise 2 in dia wrap grips used.

Table 4. Kevlar Strain-Rate Dependent Strengths for Parachute Materials

\begin{tabular}{|c|c|c|c|c|c|}
\hline $\begin{array}{c}\text { Strain Rate (1/sec) } \\
\text { Sample Type }\end{array}$ & 0.012 & $\begin{array}{r}0.12 \\
\text { verage } S\end{array}$ & 1.2 & 12 & $\begin{array}{l}\text { Percent } \\
\text { Change - } \\
\text { Slow to Fast }\end{array}$ \\
\hline $\begin{array}{l}1 \times 5000 \text { Webbing } \\
1 \times 6000 \text { Webbing }\end{array}$ & $\begin{array}{l}5573^{*} \\
6138 \\
6587^{*}\end{array}$ & 6138 & 6195 & $\begin{array}{l}5089 \\
6289\end{array}$ & $\begin{array}{l}-9 \% \\
2 \%\end{array}$ \\
\hline $2 \times 2000$ Webbing & $2586^{*}$ & & & 2373 & $-8 \%$ \\
\hline
\end{tabular}

(93 lb/in and $80.5 \mathrm{lb} /$ in for 0.012 and $121 / \mathrm{sec}$ strainrate, respectively), in the direction of fill (67 lb/in and $61 \mathrm{lb} /$ in for low and high strain-rate, respectively) and the bias direction $(70 \mathrm{lb} / \mathrm{in}$ and $30 \mathrm{lb} / \mathrm{in}$ for low and high-rate, respectively). The bias showed a change of more than a factor of 2 , while the warp and fill showed a $10-15 \%$ reduction in strength at high strain-rate. Care must be used in extending this data as not all fabrics decrease in strength at high strain-rate. Experience with other lightweight nylon fabrics has shown a dependence on the warp and fill packing construction, finishing procedures, and other production techniques. Each fabric should be tested to determine its particular moduli.

\section{Results Discussion}

In general, large changes were found between the various environmental conditions for the nylon materials. This was true for either temperature or strain-rate. The reason this is important is that the load distribution in a multi-material parachute (which is not uncommon in high performance applications) will change drastically under the conditions reported here. There is a complex, coupled interaction among load distribution, shape, and deployment. For a single material application, like a complete nylon parachute, the shape and capacity of various portions of the parachute will change depending on the conditions of use. Therefore, using only the slow speed data for parachute design could be very danger- 
When the effects of high strain-rate and temperature are combined, a strength loss of $47 \%$ from an ambient, slow speed test to a hot, high speed test is possible ( $2 \times 550$ ribbon). On average, a 35\% strength loss was found for the nylon samples when both environments were combined.

We consistently found changes of $20-26 \%$ in the nylon materials from cold to hot conditions. The conditions from ambient to either temperature extreme was also notable; variations of $10-20 \%$ in strength were common from ambient to either cold or hot temperatures.

The Kevlar materials used in parachute construction did not experience a great strength variation from temperature effects. Negligible, effects of $2-3 \%$ were found in the higher capacity materials $(5,000$ and $6,000 \mathrm{lb}$ webbing). A greater effect was found in the lighter weight $1 / 2 \times 550$ webbing ( $14 \%$ strength increase from cold to hot).

Nylon showed a great sensitivity with strain-rate. A reduction in strength of $35 \%$ across 4 decades of strainrate was found for the $2 \times 550$ ribbon. On average, reductions of $25 \%$ were found for the greater capacity ribbon and webbing.

Kevlar did not show as great a sensitivity to strain-rate. Differences of $8-9 \%$ were found for the $1 \times 5000$ webbing and the $2 \times 2000$ webbing. The $1 \times 6000$ webbing showed only a $2 \%$ variation across the 4 decades of strain-rate tested.

The nylon and Kevlar both exhibited linear strain-tofailure. This allows the use of the large deformation, linear orthotropic material constitutive models. A discussion of how to incorporate this data into an analytical model follows.
Analysis codes like ABAQUS/Explicit [4] can be used for the analysis of an opening parachute [1], or other fabric structures like the impact of the JPL Mars Pathfinder Airbag system [2], where the orthotropic nature of the fabric can be modeled in the material behavior of the structure. Codes of this type have the ability to analyze the large deformations encountered in these simulations; they necessarily use true strain because of this capability. The strains reported here are engineering strain. This section describes how the data can be used in the preparation of these types of analytical models.

Data for ribbon and webbing is commonly reported as a minimum breaking strength, in units of force. Data for fabrics is commonly reported in quantities of force/ length. Material constitutive models are expressed in term of stress and strain. The thickness of the fabric must be used to convert the stress, force/length ${ }^{2}$, into a form to communicate to and from the analysis code. An example which shows how to use this data follows:

Using the test results of $486 \mathrm{lbs}$ found from the $2 \times 550$ nylon ribbon as an example (assuming the thickness is 0.010 in and using a geometrically similar membrane element), we determine a failure stress, $\sigma$, as

$$
\sigma=\frac{486 \mathrm{lbs}}{(2 \mathrm{in} \times 0.010 \mathrm{in})}=24.3 \mathrm{ksi} \text {. }
$$

The modulus of elasticity, E, is determined by

$$
E=\frac{\sigma}{\ln \frac{l_{f}}{l_{0}}}=\frac{\sigma}{\ln \left(1+\frac{\Delta l}{l_{0}}\right)}
$$

where the term $\frac{\Delta l}{l_{o}}$ is merely the engineering strain. Assuming the strain-to-failure is $16 \%$ for this material, the modulus of elasticity to be input to the analysis code is simply,

$$
E=\frac{24.3 \mathrm{ksi}}{\ln (1+0.16)}=1.47 \times 10^{6} \mathrm{psi} .
$$

Stresses which are output from the analysis code will need to be multiplied by the area used to determine the modulus to allow comparison with the $486 \mathrm{lbs}$ breaking strength. Obviously, if a truss element is used to model this ribbon, the area of the element used to define the modulus will be multiplied by the output stress to com- 
pare with the breaking strength.

Iteration of the materials requires changing both the modulus and the thickness as these material constants are coupled. Changing the thickness only (e.g. to gain a slightly stronger material) will also change the modulus, and hence the breaking strength. This produces nonrealizable material components. Properties from the test data for the actual materials must be used when making changes to the analytical model.

For an airbag or parachute canopy, the fabric will be modeled using membrane or thin shell elements. This material has 2-dimensional properties, i.e. the breaking strength is force/length, not just the force used above for the 1-dimensional ribbon. A similar procedure for determining the modulus is used, and the output stress is multiplied by the thickness to allow comparison with the force/length breaking strength.

It should be noted that even though a linear orthotropic material behavior is appropriate for these materials (due to the linear strain-to-failure), the need for a large deformation, nonlinear analytical code is required due to the large strain. The nonlinearities come in the form of geometric nonlinearities, where large straining and contacts are usually required for the complete solution of fabric structures like airbags and parachutes.

Experience with several test/analytical evaluations of fabric structures has verified this procedure [3]. Temperature dependency of the moduli, as evidenced by the test data, does not usually affect structural analyses because the time of loading is short. Normally, the initial state of the material prior to the short duration loading is the determining factor on what moduli is appropriate.

\section{Conclusions}

We have shown a high sensitivity in the breaking strength of nylon parachute materials for both strain-rate and temperature. Maximum variations of $47 \%$, and an average of $35 \%$, were found for these combined environmental conditions. Temperature effects accounted for variations of $20-32 \%$, and strain rate effects accounted for variations of $18-35 \%$ in breaking strength. Kevlar was found to be relatively insensitive to both environmental conditions. These environmental effects must be factored into the design of high performance fabric structures to determine the true capacity of these structures in actual use. Using only ambient, slow strain-rate test data could be very dangerous for parachute design.

Due to the large difference found between the two materials tested here, load distributions and stresses in mixed material parachutes can be highly dependent on the conditions of use. Experience at Sandia has shown a great benefit from using explicit finite element analysis tools of high performance fabric structures. A method of incorporating the test data from high strain-rate testing into these analysis tools has also been demonstrated.

\section{References}

[1] A Novel CFD/Structural Analysis of a Cross Parachute, R. A. LaFarge, J. M. Nelsen, K. W. Gwinn, AIAA 94-0752, January, 1994.

[2] Structural Analyses of the JPL Martian Lander Impact, K. W. Gwinn, to be presented at 13th AIAA Aerodynamic Decelerator Systems Technology Conference, May, 1995.

[3] Airbags to Martian Landers - Analyses at Sandia National Laboratories, K. W. Gwinn, ABAQUS Users' Conference Proceedings, Hibbitt, Karlsson \& Sorensen, Inc., Pawtucket, RI, June, 1994.

[4] ABAQUS/Explicit User's Manual, Version 5.4, Hibbitt, Karlsson \& Sorensen, Inc., Pawtucket, RI, 1994. 